Profesor dr Siniša Borović, dipl. inž. Ministarstvo odbrane SCG Beograd

Mr Nevenka Tanašćuk, dipl. mat. NIS Jugopetrol Beograd

\section{AUTOMATIZOVANI SISTEM PODRŠKE ODLUCIVANJU U PROCESIMA JAVNE NABAVKE}

UDC: $658.715: 519.863$

Rezime:

U poslednjoj fazi procesa javne nabavke komisija se susreće sa problemom izbora najboljeg ponuđača, odnosno onog čija ponuda u najvećoj meri ispunjava zahteve i uslove koji su navedeni u konkursnoj dokumentaciji. Mora se doneti odluka uz uvažavanje više različitih, a često i protivrečnih kriterijuma. Za rešavanje ovakvih $i$ sličnih problema razvijen je čitav niz metoda koje pripadaju oblasti višekriterijumske analize i rangiranja.Uzimajući u obzir karakteristike problema izbora ponuđača u procesu javne nabavke, iz skupa navedenih metoda izdvojena je metoda analitičkih hijerarhijskih procesa (AHP), kao osnovna metoda za rangiranje ponuđača. Za eventualnu kontrolu izvršenog rangiranja predlaže se familija metoda PROMETHEE I-II.

Ključne reči: javna nabavka, postupak, kvalifikacija, kriterijum, ugovor.

\title{
AUTOMATIC DECISION SUPPORT IN A TENDER PROCESS
}

Summary:

In the last phase of a tender process, the Commission has a problem with choosing the best bidder, i.e. the one whose offer meets the highest requirements in the Tender documentation. A decision has to be made taking into account many different, and very often contradictory, criteria. For solving this one as well as similar problems, numerous methods, belonging to the multicriteria analysis and ranking, are developed. Taking in to account the characteristics of a problem imposed by choosing the bidder in a Tender process, one of the mentioned methods, the method of analytical hierarchy process (AHP) has been chosen as a basic method for ranking bidders. For the performed ranking control, the PROMETHEE III, method family is proposed.

Key words: tender, procedure, qualification, criteria, contract.

\section{Uvod}

Zakon o javnim nabavkama (ZJN) kao i druga zakonska i podzakonska akta, te opšta akta Naftne industrije Srbije (NIS), uslovila su potrebu da se u procesu sprovođenja javnih nabavki izradi jedinstvena, naučno zasnovana metodologija, bazirana na višekriterijumskoj analizi i automatizuje predložena metodologi- ja, koristeći najsavremenija dostupna softverska dostignuća.

Budući da je to kod nas, relativno, nova materija i u praksi još nedovoljno verifikovana, timski se pristupilo sveobuhvatnom snimanju posla. Pri tome je posebno naglašeno detaljno proučavanje i sagledavanje zakonskih i podzakonskih akata i regulative, kao i druge literature iz predmetne oblasti. Takođe, obavljene 
su konsultacije sa poznavaocima problema, pre svega iz Uprave za javne nabavke i korišćena iskustva drugih pravnih lica koja podležu ovom zakonu. Celokupan posao realizovao je projektni tim ${ }^{\mathrm{a}} 4^{\mathrm{o}}$.

\section{Analiza poslovnog procesa}

\section{OBLASTI PRIMENE PROCEDURA JAVNE NABAVKE}

Procedure Zakona o javnim nabavkama primenjuju se u oblastima nabavke dobara, radova i usluga.

Nabavka dobara obuhvata:

- kupovinu dobara (sa plaćanjem odjednom ili na rate),

- zakup dobara,

- lizing dobara (sa pravom kupovine ili bez toga prava).

Ugovor o javnoj nabavci dobara može obuhvatiti i pružanje usluga, ako su one nužno vezane za isporuku dobara (montaža, prevoz, osiguranje ili druge usluge koje u konkursnoj dokumentaciji definiše naručilac).

Nabavka radova odnosi se na:

- izvođenje radova,

- projektovanje i izvođenje radova povezanih sa specifičnim aktivnostima navedenim u Aneksu II Zakona,

- rad pri izgradnji građevinskog objekta, uzetog kao celina, koji ispunjava sve ekonomske i tehničke uslove naručioca.

U predmetu ugovora o javnoj $n a-$ bavci usluga usluge su navedene $\mathrm{u}$ aneksima I A i I B, koji su sastavni deo ZJN. Za razliku od nabavki dobara i radova kod nabavki usluga utvrđene su usluge pri čijem nabavljanju se ne primenjuju odredbe ZJN.
Imajući u vidu spektar delatnosti NIS-a, a i iz izloženog može se konstatovati da su predmet javnih nabavki skoro sva dobra, usluge i radovi predviđeni ZJN, što ovaj projekat čini izuzetno kompleksnim.

\section{OSNOVNA NAČELA JAVNIH $N A B A V K I$}

Načelo ekonomičnosti $i$ efikasnosti predviđa obavezu naručioca da preduzme mere sa ciljem da obezbedi da se postupak sprovođenja javne nabavke i izbor ponuđača vrši u rokovima i na način propisan Zakonom i sa što manje troškova vezanih za realizaciju javne nabavke.

Načelo obezbeđivanja konkurencije među ponuđačima podrazumeva:

- da naručilac ne može da ograniči konkurenciju među ponuđačima,

- da subjekti koji su pripremali konkursnu dokumentaciju, ili pojedine njene delove, ne mogu nastupati kao ponuđači ili kao podizvođači niti mogu sarađivati sa ponuđačima pri pripremanju ponude,

- da naručilac ne može od ponuđača da zahteva da kod javnih nabavki angažuje određenog podizvođača, niti da izvede neku drugu transakciju, ako posebnim zakonom ili međunarodnim sporazumom nije drugačije predviđeno, ili ako u konkursnoj dokumentaciji nije navedeno.

Načelo transparentnosti podrazumeva da su informacije o elementima postupka nabavke dostupne svim zainteresovanim ponuđačima, da je postupak otvoren za uvid ponuđača u svim svojim segmentima, i da su pravila učešća u postupku napisana razumljivo. 
Načelo jednakosti ponuđača predviđa zabranu naručiocu da određuje uslove koji bi značili:

- teritorijalnu diskriminaciju među ponuđačima,

- predmetnu diskriminaciju među ponuđačima,

- ličnu diskriminaciju među ponuđačima,

- diskriminaciju koja bi proizlazila iz klasifikacije delatnosti koju obavlja ponuđač.

VRSTE POSTUPAKA U JAVNIM NABAVKAMA

Postupci koji predstavljaju pravilo u javnim nabavkama su:

- otvoreni,

- restriktivni,

- postupak sa pogađanjem (predstavlja izuzetak od opštih pravila).

Otvoreni postupak je postupak u kojem sva lica, koja imaju interes za dobijanje ugovora o javnoj nabavci, mogu dostaviti svoje ponude u skladu sa prethodno definisanim zahtevima naručioca, predviđenim u konkursnoj dokumentaciji.

Restriktivni postupak sprovodi se u dve faze.

U I fazi zainteresovani ponuđači podnose prijave za utvrđivanje kvalifikacije. Uz prijavu ponuđači podnose dokaze o ispunjavanju propisanih statusnih, finansijskih, kadrovskih i tehničkih uslova. Rezultat završetka prve faze je lista kvalifikovanih ponuđača, koja može da bude utvrđena za period od jedne do tri godine, i koja je osnov za otpočinjanje druge faze postupka.

U II fazi kvalifikovani ponuđači podnose ponude za konkretnu nabavku.
Postupak sa pogadanjem može se sprovoditi u dva slučaja.

Bez prethodnog objavljivanja, ako zbog:

- objektivnih razloga, ili iz razloga povezanih sa zaštitom isključivih prava, nabavku mogu ispuniti samo određeni isporučioci dobara, pružaoci usluga ili izvođači radova;

- vanrednih okolnosti, odnosno zbog nepredviđenih događaja, naručilac nije mogao da postupi u rokovima određenim za otvoreni i restriktivni postupak.

Posle prethodnog objavljivanja poziva za prijavljivanje za otvoreni ili restriktivni postupak ako:

$-u$ otvorenom ili restriktivnom postupku uopšte nije dobio ponude, ili su ponude neodgovarajuće ili neprihvatljive, pod uslovom da se sadržina raspisane konkursne dokumentacije u osnovi ne menja. Naručilac mora da objavi obaveštenje da će ugovor biti dodeljen po postupku sa pogađanjem i da je u taj postupak uključio sve ponuđače čije su ponude bile date u otvorenom ili restriktivnom postupku i koje su bile u skladu sa zahtevom za priznavanje kvalifikacija;

- u izuzetnim slučajevima, kada zbog prirode nabavke naručilac ne može prethodno u celini da utvrdi cenu.

\section{KONKURSNA DOKUMENTACIJA}

Da bi se u postupku javne nabavke ostvario osnovni cilj, tj. nabavka dobara, radova ili usluga najboljeg kvaliteta, a koliko je moguće, uz što povoljniju cenu, potrebno je vrlo pažljivo pristupiti pripremi konkursne dokumentacije, u kojoj, pre svega, treba jasno, nedvosmisleno i sveobuhvatno definisati sve zahteve. 
Obim i sadržina konkursne dokumentacije zavise od:

- vrste postupka koji se sprovodi,

- predmeta nabavke.

Odredbama Zakona propisani su različiti obavezni elementi konkursne dokumentacije (konkursna dokumentacija može da sadrži i druge elemente koji su, s obzirom na predmet javne nabavke, neophodni za izradu ponude), u zavisnosti od toga za koju vrstu postupka se ona priprema.

\section{KRITERIJUMI ODLUČIVANJA I PONDERI}

Prema Zakonu o javnim nabavkama najznačajniji opšti kriterijumi za ocenjivanje ponuda odnose se na ekonomski najpovoljniju ponudu i najnižu ponuđenu cenu.

U okviru ove grupe ekonomski najpovoljnije ponude, prema čl. 55 Zakona, predviđeni su sledeći kriterijumi:

1) rok isporuke dobara, ili izvršenja usluga ili radova;

2) tekući troškovi;

3) troškovna ekonomičnost;

4) kvalitet i primena odgovarajucíh sistema QA/QC ili standarda; stike;

5) estetske i funkcionalne karakteri-

6) tehničke i tehnološke prednosti;

7) postprodajno servisiranje i tehnička pomoć;

8) garantni period, vrsta i kvalitet garancija i garantovane vrednosti; lova;

9) obaveze u pogledu rezervnih de-

10) postgarancijsko održavanje;

11) ponuđena cena;

12) mogućnosti tipizacije i unifikacije; i dr.

13) obim angažovanja podizvođača,

Specifični kriterijumi zavise, prvenstveno, od predmeta nabavke (dobra, usluge, radovi). Njihov izbor, rangiranje i dodeljivanje pondera zavisi od opredeljenja komisije. Specifični kriterijumi, takođe, moraju biti opisani, vrednovani, ne smeju biti diskriminatorski i moraju biti u logičnoj vezi sa predmetom nabavke.

Mogući specifični kriterijumi su:

1) tekući troškovi (održavanje, povezani troškovi i dr.);

2) kvalitet i primena odgovarajućih sistema kvaliteta;

3) estetske i funkcionalne karakteristike;

4) tehničke i tehnološke prednosti;

5) postprodajno servisiranje $i$ tehnička pomoć;

6) obaveze u pogledu rezervnih delova;

7) postgarancijsko održavanje;

8) mogućnost tipifikacije i unifikacije;

9) obim angažovanja podizvođača;

10) obaveze u pogledu obuke radnika;

11) reference stručnih lica koja će biti angažovana (broj i vrsta);

12) posedovanje, vrsta i izdavalac ISO sertifikata, itd.

Razrađen je algoritamski blok-dijagram tokova informacija i dokumentacije u procesu javne nabavke, a saglasno $\mathrm{ZJN}{ }^{\mathrm{a}} 4^{\circ}$. U ovom radu prikazan je samo deo blok-dijagrama (slike 8 i 9).

\section{Rešenje problema primenom višekriterijumske analize}

U poslednjoj fazi procesa javne nabavke komisija se susreće sa problemom izbora najpovoljnijeg ponuđača, $\mathrm{tj}$. onog 
čija ponuda $u$ najvećoj meri ispunjava zahteve i uslove koji su navedeni u konkursnoj dokumentaciji. Mora se doneti odluka uz uvažavanje više različitih, a često i protivrečnih kriterijuma. Poblem je trivijalan ako je konkurisao mali broj ponuđača, ili ako neveliki broj ponuda ispunjava sve zahteve i uslove iz konkursne dokumentacije. Međutim, realne situacije su obično složenije. Najčešće postoji veći broj ponuđača čije ponude zadovoljavaju postavljene zahteve, pa se postavlja pitanje kako iz skupa približno jednako dobrih ponuđača odabrati najboljeg, uz uvažavanje definisanih kriterijuma. Problem se dalje komplikuje činjenicom da nisu svi kriterijumi iste važnosti, niti im se dodeljuju iste vrednosti pondera, kao i čest slučaj kada vrednosti kriterijuma nisu kvantitativne, već su izražene kvalitativno. Takođe, i mišljenja svih članova komisije nemaju istu težinu $\mathrm{i}$ značaj.

Opisani problemi sa kojima se susreće komisija predstavljaju tipičan zadatak višekriterijumske analize i rangiranja, sa sledećim karakteristikama: ponuđača,

- veći broj varijanti za odlučivanje -

- veći broj kriterijuma po kojima se donosi odluka,

- postojanje konflikta kriterijumima,

- nejednaka važnost kriterijuma,

- neuporedivost jedinica mere - vred-

nosti kriterijuma izražene su u različitim jedinicama mere,

- kvalitativne vrednosti kriterijuma - vrednosti pojedinih kriterijuma mogu se izraziti samo opisno.

Za rešavanje ovakvih i sličnih problema razvijen je niz metoda koje pripa- daju oblasti višekriterijumske analize i rangiranja - VišeAtributnom Odlučivanju (VAO).

Metoda VAO omogućava da se iz skupa ponuđenih izabere najprihvatljivija varijanta $a^{*}$, a na osnovu definisanih kriterijuma. U modelima VAO kriterijumi su zadati atributima. Postoji konačan broj unapred zadatih varijanti za izbor, pri čemu ne postoje eksplicitno definisana ograničenja, već su ona uključena u atribute.

Model VAO odgovara loše struktuiranim problemima i ima sledeću opštu postavku:

$$
(\max )\left\{f_{1}(x), f_{2}(x), \ldots, f_{n}(x), \quad n \geq 2\right\}
$$

uz ograničenja:

$x \in A=\left[a_{1}, a_{2}, \ldots, a_{m}\right]$

gde je:

$n$-broj kriterijuma (atributa), $j=1,2, \ldots, n$, $m$-varijante (akcije), $i=1,2, \ldots, m$,

$f_{j}$ - kriterijumi (atributi), $j=1,2, \ldots, n$,

$a_{i}$ - varijante (akcije) za razmatranje, $i=1,2, \ldots, m$,

$A$ - skup svih varijanti.

Pri tome su poznate i vrednosti $f_{i j}$ svakog razmatranog kriterijuma $f_{j}$, dobijene sa svakom od mogućih varijanti

$a_{i}: f_{i j}=f_{j}\left(a_{i}\right),(i, j)$.

Model VAO se na ustaljeni način prikazuje preko matrice, koja se naziva matricom odlučivanja:

VAO je oblast koja se ubrzano razvijala u poslednjih dvadeset godina. Kao odgovor na rastuću kompleksnost realnog sveta razvijani su različiti modaliteti kretanja kroz realne probleme čija su glavna obeležja kompleksnost, dinamič- 
Matrica odlučivanja

\begin{tabular}{|c|c|c|c|c|c|c|}
\hline \multirow{2}{*}{\multicolumn{2}{|c|}{$\mathrm{j}$}} & \multicolumn{5}{|c|}{ Kriterijumi } \\
\hline & & \multirow{2}{*}{$\begin{array}{l}f_{1} \\
f_{11}\end{array}$} & \multirow{2}{*}{$\ldots$} & \multirow{2}{*}{$\frac{f_{j}}{f_{1 j}}$} & \multirow{2}{*}{$\ldots$} & \multirow{2}{*}{$\begin{array}{l}f_{n} \\
f_{1 n}\end{array}$} \\
\hline \multirow{5}{*}{ 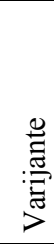 } & $\mathrm{A}_{1}$ & & & & & \\
\hline & $\ldots$ & & & & & \\
\hline & $\mathrm{A}_{\mathrm{i}}$ & $\mathrm{f}_{\mathrm{i} 1}$ & & $f_{i j}$ & & $\mathrm{f}_{\text {in }}$ \\
\hline & $\ldots$ & & & & & \\
\hline & $A_{m}$ & $f_{m 1}$ & & $f_{m j}$ & & $f_{m n}$ \\
\hline \multicolumn{2}{|l|}{$\mathrm{W}_{\mathrm{j}}$} & $\mathrm{W}_{1}$ & & $\mathrm{~W}_{\mathrm{j}}$ & & $\mathrm{W}_{\mathrm{n}}$ \\
\hline \multicolumn{2}{|l|}{$+/-$} & & & & & \\
\hline
\end{tabular}

nost i višeznačnost. Razvijeno je više metoda za rešavanje problema VAO (posebno višekriterijumskog rangiranja), među kojima se posebno mogu izdvojiti: ELECTRE, VIKOR, AHP, PROMETHEE i dr.

\section{IZBOR METODE ZA REŠAVANJE PROBLEMA}

Pri rešavanju realnog problema, pored definisanja relevantnih kriterijuma, postavlja se pitanje izbora odgovarajućeg metoda. U savremenoj literaturi apostrofirana su dva kriterijuma kao posebno značajna sa aspekta korisnika-donosioca odluke, u izboru višekriterijumskog metoda, a to su lakoća korišćenja i razumljivost.

Izbor najboljeg višekriterijumskog metoda u potpunosti je determinisan karakteristikama samog problema, nivoom kompleksnosti kao i iskustvom korisnika.

Kada su evidentirane sve varijante, bira se metod dovoljno reprezentativan, obuhvatan i kompleksan da vrši vrednovanje, selekciju i izdvajanje najboljeg ili traženog broja varijanti.

Uzimajući u obzir karakteristike problema izbora ponuđača u procesu jav- ne nabavke, iz skupa navedenih metoda izdvaja se metoda Analitičkih Hijerarhijskih Procesa (AHP), kao osnovna metoda za rangiranje ponuđača. Kao metoda za eventualnu kontrolu izvršenog rangiranja predlaže se familija metoda PROMETHEE I-II.

\section{KARAKTERISTIKE MODELA VIŠEATRIBUTNOG ODLUČIVANJA (VAO)}

Za modele VAO, nezavisno od metode koja se koristi za rešavanje problema, značajni su sledeći aspekti:

- kvantifikacija kvalitativnih atributa,

- modifikacija atributa istog kriterijuma,

- normalizacija i linearizacija atributa,

- definisanje težinskih koeficijenata kriterijuma.

\section{Kvantifikacija kvalitativnih atributa}

U realnim problemima koji se rešavaju metodama višekriterijumskog rangiranja, priroda kriterijuma je često takva da kriterijumske vrednosti varijanti nije moguće izraziti brojnim vrednostima, već se one izražavaju opisno. Rešavanje modela VAO u opštem slučaju zahteva korišćenje kvantitativnih brojnih podataka, tako da ih je, u slučajevima kada postoje kvalitativni (opisni) podaci, potrebno pretvoriti u brojne podatke. $U$ tu svrhu razvijeno je i u praksi se primenjuje više metoda, kao što su linearna skala za kvantifikaciju kvalitativnih atributa i ekspertsko ocenjivanje.

Kvantifikacija atributa koji imaju kvalitativna obeležja, primenom linearne 
Linearna skala transformacija:

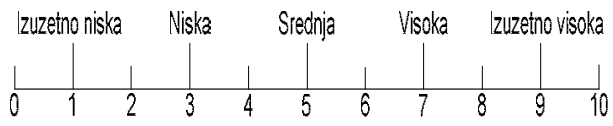

Sl. 1 - Linearna skala kvantifikacije

skale transformacija, vrši se jednostavnim utvrđivanjem brojne vrednosti atributa u skladu sa prethodno definisanom skalom brojnih vrednosti (slika 1).

Ekspertske ocene su subjektivne ocene vrednosti pojedinih kriterijuma koje daju eksperti (članovi komisije), zasnovane na stručnosti i iskustvu u datoj oblasti, a daju se u nekom rasponu ocena, na osnovu kojih se formira jedinstvena grupna ocena.

\section{Normalizacija i linearizacija atributa}

Normalizacija i linearizacija kriterijumskih vrednosti varijanti vrši se radi upoređivanja kriterijuma različitih vrednosti i različitih jedinica mere. Osnovni smisao ove transformacije atributa jeste eliminisanje jedinica mere i svođenje kriterijumskih vrednosti na bezdimenzionalne vrednosti. Uobičajeno je da se u nekom od koraka metode VAO koristi neki od postupaka vektorske normalizacije ili linearne skale transformacije.

Vektorska normalizacija:

$$
r_{i j}=\frac{f_{i j}}{\sqrt{\sum_{i=1}^{m} f_{i j}^{2}}}, \text { za max } f_{j} \text {, }
$$

$$
r_{i j}=1-\frac{f_{i j}}{\sqrt{\sum_{i=1}^{m} f_{i j}^{2}}},
$$

za prevođenje $\min f_{j} \mathrm{u} \max f_{j}$ $l_{i j}=\frac{f_{i j}}{f_{j}^{\max }}, \quad$ za $\max f_{j}$,

$l_{i j}=1-\frac{f_{i j}}{f_{j}^{\max }}, \quad$ ili $l_{i j}=\frac{f_{i j}}{f_{j}^{\min }}$

za $\min f_{j} \Rightarrow \max f_{j}$

ili

$l_{i j}=\frac{f_{i j}-f_{j}^{\min }}{f_{j}^{\max }-f_{j}^{\min }}, \quad$ za $\max f_{j}$,

$l_{i j}=\frac{f_{j}^{\max }-f_{j}^{\min }}{f_{i j}-f_{j}^{\min }}$ za $\min f_{j} \Rightarrow \max f_{j}$

gde su:

$\mathrm{f}_{\mathrm{j}}^{\max }=\max \left(\mathrm{f}_{\mathrm{ij}}, \mathrm{i}=1,2, \ldots, \mathrm{m}\right)$;

$\mathrm{f}_{\mathrm{j}}^{\min }=\min \left(\mathrm{f}_{\mathrm{ij}}, \mathrm{i}=1,2, \ldots, \mathrm{m}\right)$.

Definisanje težinskih koeficijenata kriterijuma - pondera

Određivanje relativnih težina kriterijuma u modelima višekriterijumskog odlučivanja uvek predstavlja specifičan problem koji je neminovno praćen subjektivnostima. Ovaj postupak veoma je značajan i ima bitan uticaj na krajnji rezultat odlučivanja. Realni problemi najčešće nemaju kriterijume istog stepena značajnosti, zbog čega je potrebno definisati faktore značajnosti pojedinih kriterijuma koristeći odgovarajuće težinske koeficijente (težine) ili tzv. pondere za kriterijume. Ako njihov zbir iznosi 1 to su normalizovane težine. Problemu određivanja težina kriterijuma mora se posvetiti posebna pažnja. Pretpostavlja se da 
komisiju čini grupa eksperata koja radi na pripremi dokumentacije i na pripremi odluke, pa je problem određivanja težina kriterijuma moguće rešiti primenom metoda ekspertskog ocenjivanja.

\section{KARAKTERISTIKE IZABRANIH METODA VAO}

\section{Metoda analitičkih hijerarhijskih procesa-AHP}

Analitički Hijerarhijski Proces (AHP), koji je razvio Tomas Saaty početkom sedamdesetih godina dvadesetog veka, predstavlja alat u analizi odlučivanja, kreiran da pruži pomoć donosiocima odluke u rešavanju kompleksnih problema odlučivanja u kojima učestvuje veći broj donosilaca odluke, veći broj kriterijuma i u višestrukim vremenskim periodima. Razvijen je originalan softver iz klase sistema za podršku odlučivanju Expert Choice. Metoda AHP provodi se kroz četiri faze.

1. Struktuiranje problema sastoji se od dekomponovanja bilo kog složenog problema odlučivanja u seriju nivoa, pri čemu svaki nivo predstavlja manji broj upravljanih atributa.

2. Prikupljanjem podataka i njihovim merenjem otpočinje druga faza metode AHP. Donosilac odluke dodeljuje relativne ocene u parovima atributa, jednog hijerarhijskog nivoa i to za sve nivoe celokupne hijerarhije. Pri tome se koristi (do sada najpoznatija) skala devet tačaka. Završetkom ovog procesa dobija se odgovarajuća matrica upoređivanja po parovima koji odgovaraju svakom nivou hijerarhije.
3. Procena relativnih težina je treća faza metode AHP. Matrica poređenja, po parovima, prevodi se u probleme određivanja sopstevenih vrednosti, radi dobijanja normalizovanih i jedinstvenih sopstvenih vektora, težina za sve atribute na svakom nivou hijerarhije.

4. Određivanje rešenja problema podrazumeva nalaženje tzv. kompozitnog normalizovanog vektora. Pošto se odredi vektor redosleda vrednosti kriterijuma u modelu, određuje se, u okviru svakog posmatranog kriterijuma, redosled važnosti varijanata u modelu. $\mathrm{Na}$ kraju, izvodi se sveukupna sinteza problema, tako što se učešće svake varijante množi sa težinom posmatranog kriterijuma, a zatim se te vrednosti saberu za svaku varijantu posebno. Dobijeni podatak predstavlja težinu posmatrane varijante $u$ modelu. Na osnovu dobijenih podataka za težine svih varijanata određuje se njihov poredak.

Pored opisanog osnovnog postupka metode AHP postoji i varijanta provođenja metode sa unapred definisanim kvantitativnim kriterijumskim vrednostima varijanti i definisanim vrednostima pondera.

U slučaju izbora ponuđača u procesu javne nabavke postoje kvantitativne vrednosti kriterijumskih vrednosti varijanti (to su vrednosti kriterijuma sadržani u ponudama) i definisane vrednosti pondera kriterijuma, pa se može primeniti varijanta metode AHP sa matricom odlučivanja sa kvantifikovanim vrednostima kriterijuma. Procedura ove varijante AHP je određena na sledeći način:

1. Struktuiranje problema i formiranje stabla potpuno su isti kao i u osnovnoj varijanti metode. 
2. Za svaki kriterijum računa se normalizovana vrednost njegovog pondera:

$$
w_{j}=\frac{W_{j}}{\sum_{j=1}^{n} W_{j}}
$$

3. Za svaki kriterijum posebno računa se zbir kriterijumskih vrednosti varijanti $a_{i j}$ :

$s_{j}=\sum_{i=1}^{m} a_{i j}$,

a zatim se elementi matrice $a_{i j}$ transformišu u elemente

$$
a_{i j} *=\frac{a_{i j}}{\sum_{i=1}^{m} a_{i j}}, \quad(j=1, \ldots, n)
$$

koji predstavljaju učešće svake varijante u okviru posmatranog kriterijuma.

Za kriterijume za koje se određuje minimalna vrednost sabiraju se recipročne vrednosti kriterijumskih vrednosti varijanti.

4. Sveukupna sinteza problema izvodi se tako što se učešće svake varijante množi sa težinom posmatranog kriterijuma, a zatim se te vrednosti saberu za svaku varijantu posebno. Dobijeni podatak predstavlja težinu posmatrane varijante $u$ modelu. $\mathrm{Na}$ osnovu dobijenih podataka za težine svih varijanata određuje se njihov poredak.

\section{Skup metoda PROMETHEE I-III}

Skup metoda PROMETHEE - Preference Ranking Organization METHods for Enrichment Evaluation, razvio je J. P.
Brans sa svojim saradnicima 1984. godine i one se neprestano usavršavaju. Metode su namenjene za rangiranje elemenata nekog skupa pri višekriterijumskom odlučivanju.

Metoda PROMETHEE I daje parcijalni poredak elemenata ili varijanata, PROMETHEE II određuje potpuni poredak, a metoda PROMETHEE III daje intervalni poredak elemenata. Familija metode PROMETHEE zasnovana je na uopštavanju pojma kriterijuma sa šest tipova generalizovanih kriterijumskih funkcija, i na osnovu njih definisanim matematičkim relacijama za rangiranje. Metoda omogućava i uvođenje težina za pojedine kriterijume. Postupak provođenja metode sastoji se od sledećih koraka:

1) Formiranje početne matrice - početne matrice za VAO.

2) Izbor tipa generalizovane kriterijumske funkcije u skladu sa definisanim tipovima generalizovanih kriterijumskih funkcija.

3) Određivanje višekriterijumskog indeksa preferentnosti na osnovu vrednosti jednokriterijumskih indeksa preferentnosti dobijenih u zavisnosti od tipa generalizovane kriterijumske funkcije.

4) Definisanje relacija rangiranja $u$ zavisnosti od tipa metode i rangiranja varijanti.

\section{Arhitektura informacionog podsistema za javne nabavke}

Postavljanjem arhitekture određenog Informacionog PodSistema (IPS) gradi se i podloga za koordinirani razvoj aplikacija i baze podataka, a u skladu sa potrebama neposrednih korisnika i raspoloživim resursima. Dizajniranje arhitekture informacionog podsistema za $\mathrm{JN}$ ba- 
zira se na Modelu podataka i Modelu funkcija. Informacioni podsistem $\mathrm{JN}$ sadrži module i procese čiji je opseg definisan grupama poslovnih funkcija.

Definisanje baze matičnih kataloga obuhvata:

- organizacione jedinice (delovi NIS-a kao i niži nivoi),

- poslovne partnere (ponuđače),

- ugovore,

- izveštavanje iz matičnih kataloga:

- interaktivno,

- batch.

Definisanje baze kriterijuma odlučivanja čine:

- opšti kriterijumi,

- potkriterijumi nižih nivoa,

- izveštavanje po osnovu kriterijuma:

- interaktivno,

- batch.

$\mathrm{U}$ fazi pripreme konkursne dokumentacije tenderska komisija definiše kriterijume za ocenu prispelih ponuda, a u skladu sa karakteristikama predmeta javne nabavke.

$\mathrm{Na}$ slici 2 dat je primer razloženog kriterijuma sa prvog nivoa.

Obrada kriterijuma obuhvata:

- evidentiranje kriterijuma za konkretnu nabavku,

- određivanje težina izabranih kriterijuma,

- normalizaciju kriterijuma,

- zaključivanje kriterijuma.

Saglasno ZJN u fazi pripreme tenderske dokumentacije dodeljuju se i vrednosti pondera kriterijuma, odnosno određuje se relativna važnost svakog kriterijuma. Procedure višekriterijumskog rangiranja uslovljavaju normalizaciju kriterijuma (o čemu je bilo više reči u poglavlju Normalizacija i linearizacija atributa). Na slici 3 dat je primer normalizovanih vrednosti pondera kriterijuma.

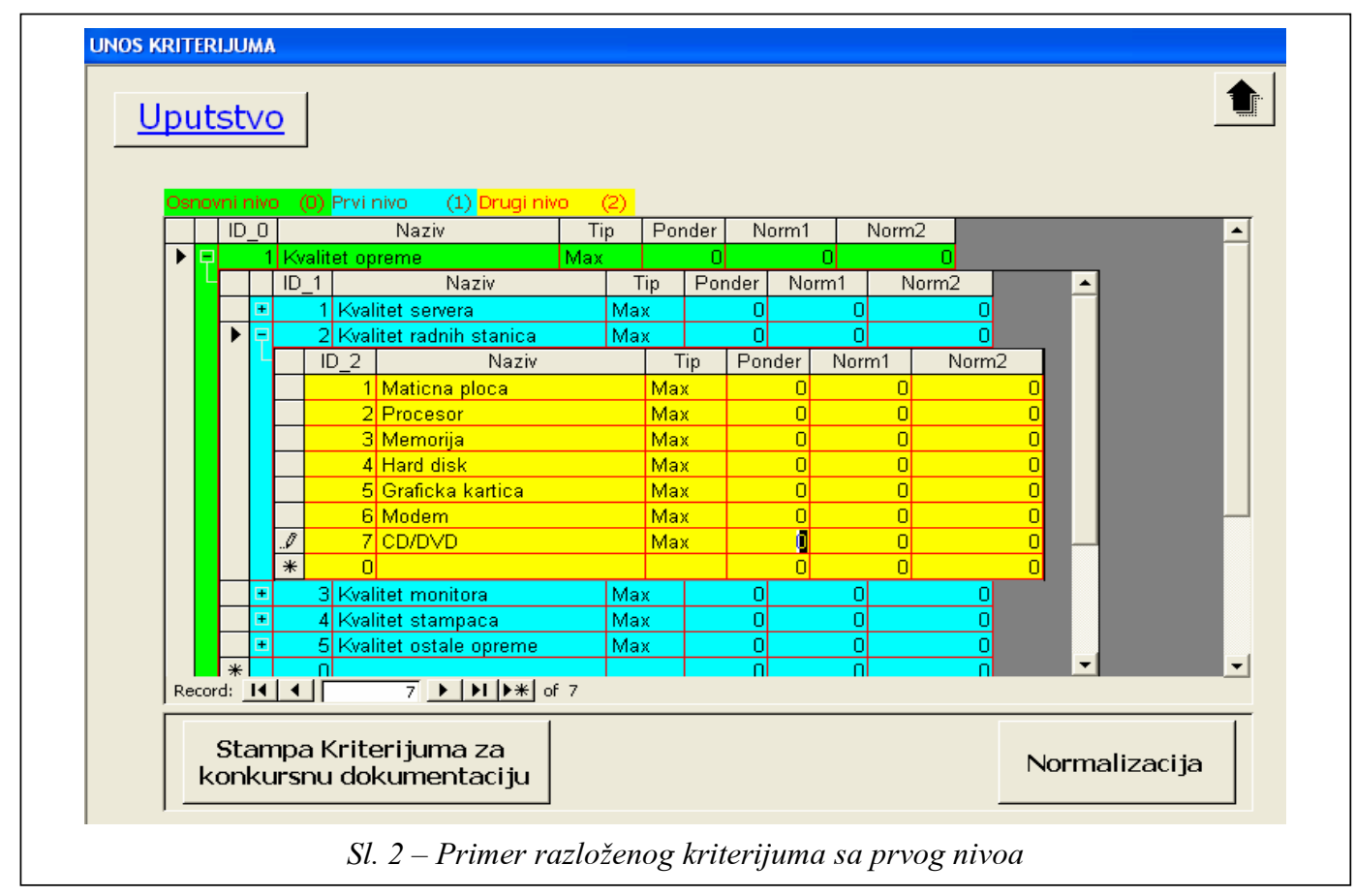



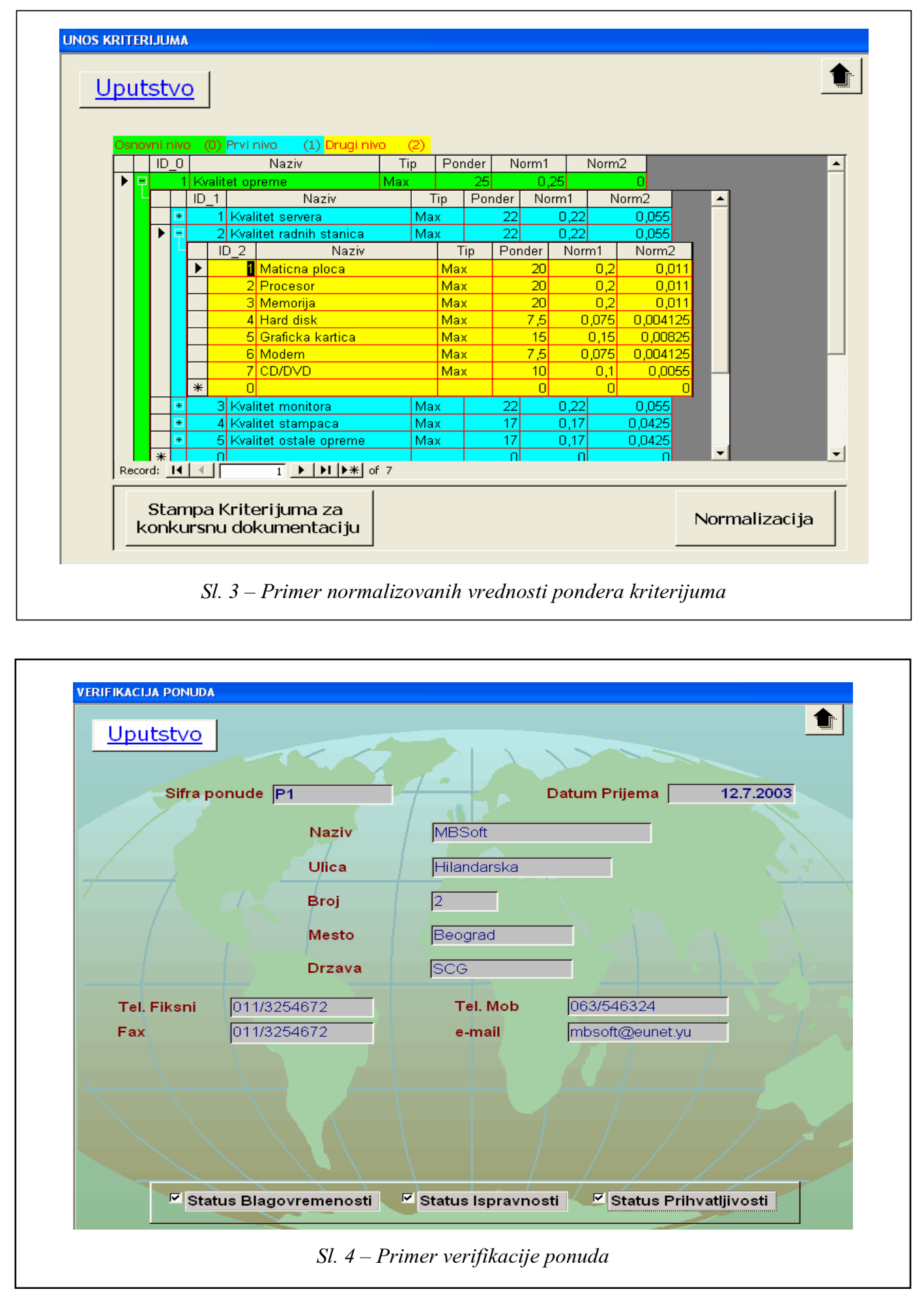
Obrada ponuda obuhvata:

- interaktivno evidentiranje ponuda,

- interaktivno pretraživanje ponuda,

- verifikaciju ponuda,

- zaključivanje ponuda.

U drugoj fazi rada komisije prispele ponude se otvaraju i evidentiraju u bazi podataka, nakon čega se vrši njihova verifikacija. Na slici 4 dat je primer verifikacije ponuda. hvata:

Izbor najpovoljnijeg ponuđača obunosti,
- VKR - poredak ponuđača,

- grafički prikaz poretka ponuđača,

- štampu poretka ponuđača,

- štampu međurezultata po pojedinačnim kriterijumima.

U sledećoj fazi obrade JN vrši se unos vrednosti kriterijuma za svaku ponudu pojedinačno, pri čemu se koristi i skala za kvantifikaciju. Na slici 5 dat je primer forme za unos vrednosti kriterijuma.

Nakon unosa vrednosti kriterijuma za sve verifikovane ponude realizuje se opcija višekriterijumskog rangiranja, ko-

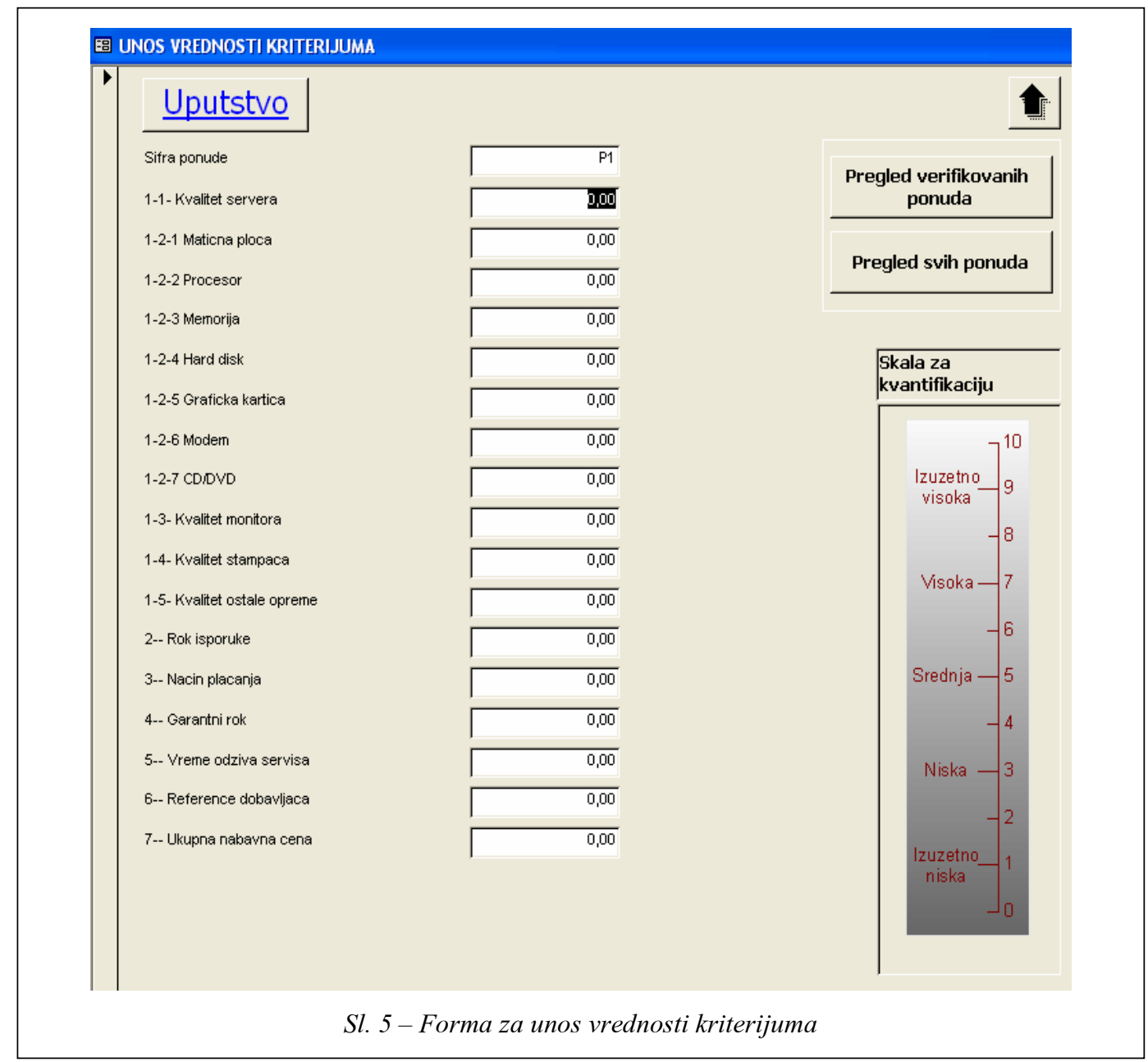


ja rezultira tabelarnim poretkom ponuđača, kao i grafičkim prikazom.

Na slikama 6 i 7 prezentiran je tabelarni i grafički prikaz ponuđača respektivno.

Kontrola rezultata višekriterijumskog rangiranja ponuđača realizovana je, za sada, u DOS okruženju, pri čemu je primenjen skup naučnih, u praksi verifikovanih metoda PROMETHEE I-III.

Javne nabavke (JN) obuhvataju:

- evidentiranje podataka o $\mathrm{JN}$,

- izveštavanje po osnovu JN:

- interaktivno,

- batch.

Arhiviranje podataka o JN obavlja se u bazi podataka, i na osnovu njih vrši se odgovarajuće izveštavanje koje je: za-

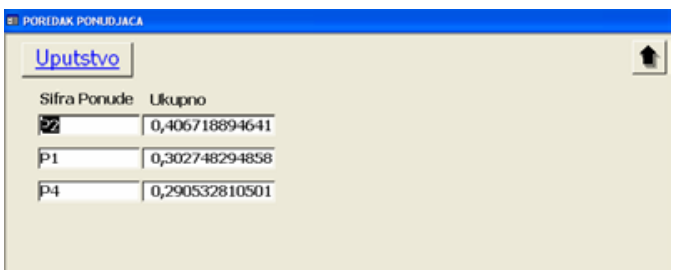

Sl. 6 - Tabelarni poredak ponuđača

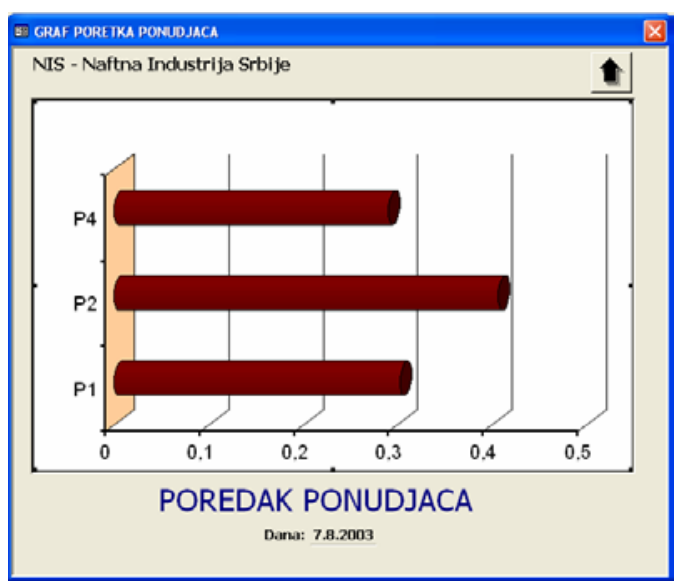

Sl. 7 - Grafički prikaz ponuđača konom propisano, operativno i obuhvatno izveštavanje poslovodstva.

Zakon o JN obavezuje arhiviranje podataka.

Operativno izveštavanje obuhvata:

- zakonom propisani obrazac A za podnošenje podataka o $\mathrm{JN}$,

- zakonom propisani obrazac B za podnošenje podataka o JNMV(Javne Nabavke Male Vrednosti),

- specifikacije ponuda,

- specifikaciju JN po: vrsti postupka, vrsti predmeta, predmetima, ponuđačima, datumu i sl.

Izveštavanje poslovodstva specificira se iz operativnih izveštaja ili se definišu novi izveštaji shodno zahtevima.

Priprema i izrada konkursne dokumentacije, prema planu, treba da se koliko to bude moguće, tipizuje i automatski priprema.

Ona obuhvata:

- javni poziv za oglašavanje $u$,Službenom glasniku RS“ i dnevnom listu,

- uputstvo ponuđačima i obrazac ponude,

- uputstvo i obrazac za kvalifikaciju,

- obrazac izjave o prihvatanju uslova iz javnog poziva i konkursne dokumentacije,

- opšte uslove ili model ugovora,

- obrazac sa elementima profakture,

- obrazac garancije za ponudu,

- obrazac garancije za dobro izvršenje posla,

- tehničku dokumentaciju.

Budući da se očekuju zakonske izmene, aktivnosti u vezi s automatizacijom pripreme konkursne dokumentacije odložene su za kasnije. 


\section{Model podataka informacionog sistema}

\section{Osobine modela}

Pri kreiranju modela podataka koji se odnosi na poslove JN u NIS-u rukovodilo se osnovnim načelima izrade integralnog modela podataka jednog informacionog sistema, a to su:

- sveobuhvatnost - model podataka sadrži sve bitne podatke neophodne za uspešno odvijanje poslovnih procesa;

- jednoznačnost - svaki podatak u sistemu se obuhvata samo jedanput;

- verodostojnost - radi izbegavanja mogućih grešaka i drugih nedostataka intencija je da se podaci obuhvataju, po mogućnosti, na mestu njihovog nastanka;

- nezavisnost - model podataka je nezavisan od postojeće organizacione strukture poslovnog sistema i odražava realnost samog poslovanja;

- fleksibilnost - model se gradi na bazi snimljenog postojećeg stanja, ali omogućava prilagođavanja i dopune koje proisteknu iz eventualnih izmena ili proširenja funkcija poslovanja;

- efikasnost - sadržaj modela podataka pruža dovoljno informacija da se iz njega mogu relativno brzo i lako dizajnirati baze podataka, odnosno entiteti i pripadajući atributi;

- model je nezavisan i od hardvera $\mathrm{i}$ softvera, kao i načina na koji će biti realizovana baza podataka.

\section{Opseg modeliranja}

Modeliranjem je obuhvaćeno kompletno poslovanje vezano za JN, iako će se realizacija automatizacije odvijati po segmentima. Logički model podataka za projekat $\mathrm{JN}$ rađen je korišćenjem CASE alata ERwin (programski paket ERwin je proizvod U. S. firme PLATINUM tehnology). ERwin podržava IDEF1X i IE (Information Engeenering) metode, a podaci modelirani ovim metodama lako su preinačivi u relacioni model podataka na kome se zasnivaju relacione baze podataka. Pomoćnim alatima, u okviru CASE alata, moguće je pregledati i štampati različite delove ERM dijagrama, a što je od posebnog značaja za deo tima za realizaciju projekta.

Opšti nivo modela sadrži:

- dijagram entiteta i veza (The Entity Relationship Diagram - ERD), tj. pregled entiteta i njihovih veza;

- relacioni model (The Key Based model - KB) koji obuhvata skup informacija o entitetima iz modela sa postavljenim ključevima.

Niži nivo modela sadrži:

- detaljni model atributa (The Fully Attributed model - FA) sa opisima podataka;

- transformacioni model (The Transformation Model - TM).

Ovakav način organizacije podataka omogućava automatsko, efikasno i brzo izveštavanje o entitetima, atributima i relacijama na svim nivoima.

Budući da NIS, kao i svi njegovi organizacioni delovi, imaju automatsku obradu, to su matični katalozi već definisani, pa se neće, ovom prilikom, detaljnije razmatrati. To su, pre svega: katalog korisnika projekta, katalog organizacionih jedinica, katalog poslovnih partnera i katalog ugovora.

Ostali najkarakterističniji entiteti iz domena javnih nabavki odnose se na: kriterijume odlučivanja, status tendera, ponude i javne nabavke. 


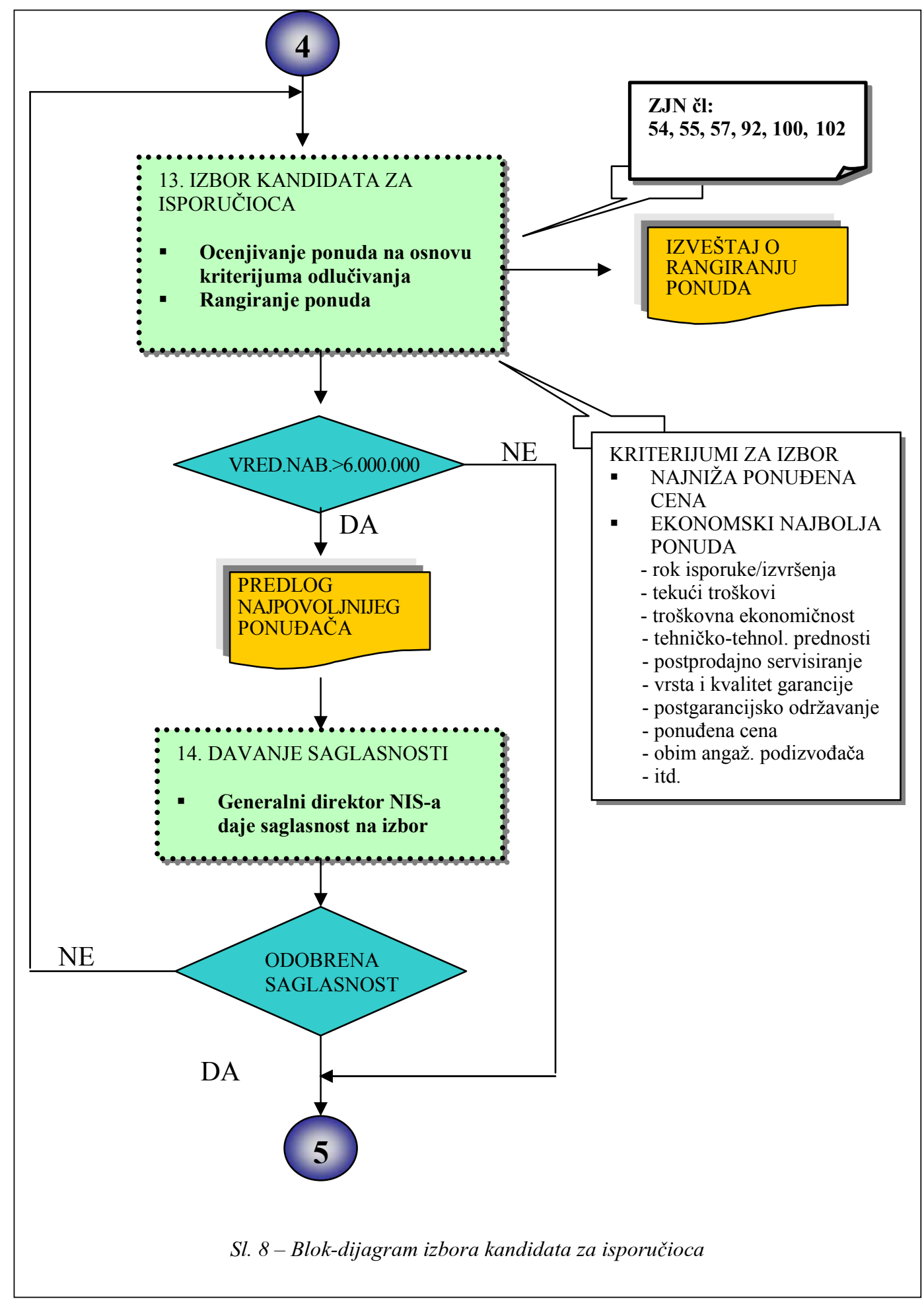




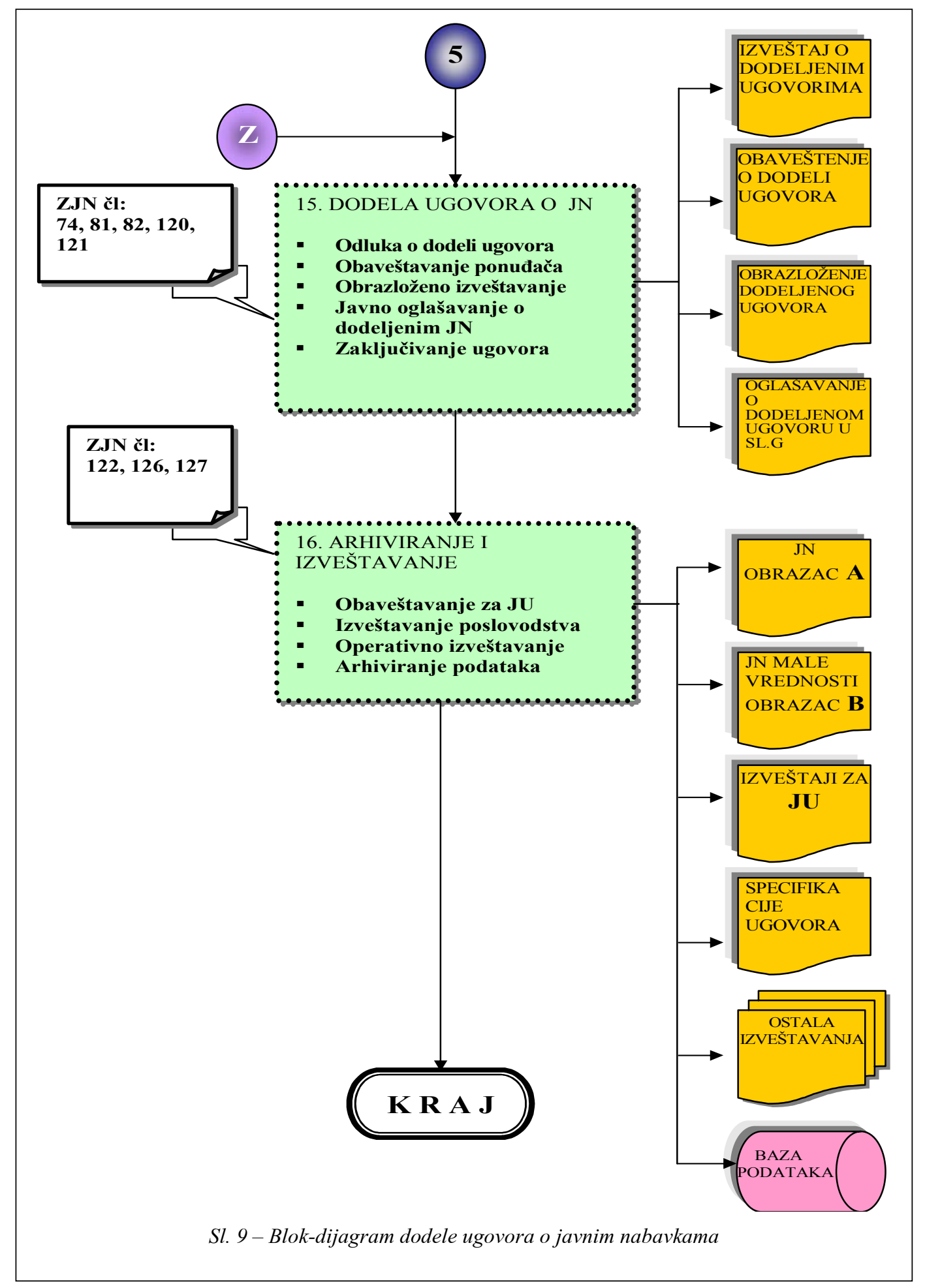




\section{Realizacija izvođačkog projekta}

Logički model podsistema JN, definisan glavnim projektom, čini osnovu realizacije konceptualnog modela $\mathrm{JN} u$ informatički model, a koji daje podršku poslovnim procesima praćenja JN u NIS-u.

Budući da su JN, zbog sistema zaštite informacija, relativno zatvoren sistem, to je realizacija urađena na PC, odnosno Client-Server platformi. Aplikacije su objektno orijentisane sa Access 2002 bazom podataka.

Izvođački projekat odvijao se kroz sledeće faze:

1) Fizički dizajn. Osnovni zadatak ove faze je analiza mogucíh pristupa $\mathrm{u}$ realizaciji logičkog dizajna, a obuhvata $i$ aktivnosti:

- integraciju logičkog modela sa modelom mreže, hardverom i softverom,

- topologiju izvršavanja (lokacija programa i procedura),

- konfiguraciju i način rada komunikacione mreže, kao i procenu izvodljivosti transakcija,

- help-desk koordinaciju, štite i sl.

- back-up i recovery proceduru, za-

- standarde (razvoj i okruženje).

2) Implementacija fizičkog dizajna obuhvata razvoj programa i procedura na razvojnom okruženju.

3) Testiranje se poklapa sa fazom razvoja softvera $i$ odigrava se na testnom okruženju, čija je konfiguracija približna ciljnoj, tj. produkcionoj.

4) Obuka korisnika. Tim za realizaciju projekta treba da izvrši obuku određenog broja kadrova, koji će činiti bazu instruktorskog kadra za dalju obuku članova tenderskih komisija. Ova faza obuhvata, takođe, i izradu odgovarajućih korisničkih uputstava za rad sa Projektom JN.
5) Uvođenje podsistema. Ova faza obuhvata aktivnosti uvođenja projekta na selektovanim lokacijama, obuku odgovarajućeg kadra, produkciono testiranje, kao i definitivnu predaju projekta sa pripadajućim uputstvima i drugom dokumentacijom.

Projekat je u najvećem delu realizovan i već se primenjuje u praksi, a predstoji kompletiranje izveštajnog modula, kao i zvanična primopredaja korisniku.

\section{Zaključak}

Savremene računarske tehnike i tehnologije omogućavaju automatizaciju aktivnosti i procesa koji se odnose na javne nabavke, uz primenu naučno zasnovanih metoda višekriterijumske analize i odlučivanja. Dosledna primena pomenute tehnologije treba da omogući jednostavniji, efikasniji i objektivniji rad tenderske komisije, kao i koordinaciju i sinhronizaciju delovanja svih njenih članova.

Značaj je utoliko veći što je automatizovana relativno nova oblast privredne aktivnosti, pri čemu su primenjene najnovije, naučno zasnovane i u praksi proverene metode višekriterijumske optimizacije.

Projekat je razvijen tako da se može primeniti u različitim slučajevima nabavke dobara, usluga i radova, a ne samo u javnim preduzećima.

\footnotetext{
Literatura:

${ }^{\mathrm{a}} 1^{\mathrm{o}}$ Nikolić I.; Borović, S.: Višekriterijumska optimizacija, Beograd, 1996.

${ }^{\mathrm{a}} 2^{\circ}$ Borović, S; i Đukić, R.: Priprema odluke u nabavci tehničkih sredstava primjenom familije metoda PROMETHEE, Beograd, 1988.

${ }^{\mathrm{a}} 3^{\circ}$ Brans, J. P.: A Familly of Outranking Methods in Multicriteria Analysis, Operational Research '84, North Holland, 1984. a $4^{\circ}$ Automatizacija JN u NIS-u, Projektni tim, 2003.
} 
